\title{
APLICAÇÃO DO CICLO DE RANKINE ORGÂNICO EM MÁQUINAS AGRÍCOLAS PARA RECUPEÇÃO ENERGÉTICA DOS GASES DE ESCAPE
}

\author{
Dijalma Joaquim de Oliveira Junior ${ }^{1,1}$, Felipe dos Santos Antonele ${ }^{1,2}$, Robson Expedito dos \\ Reis $^{1,3}$, Kaique de Lima Onofre ${ }^{1,4}$, Elídio Falsin Neto ${ }^{1,5}$, Fábio Di Grigoli Antunes de \\ Menezes $^{1,6}$ e Cleber Willian Gomes ${ }^{2}$ \\ ${ }^{1}$ Centro Universitário da Fundação Educacional Inaciana Pe Sabóia de Medeiros (FEI) - \\ Engenharia Mecânica Automobilística, Brasil \\ ${ }^{2}$ Ford Motor Company ${ }^{\circledR}$ - Engenheiro \\ E-mails: ${ }^{1,1}$ dyjeta 32@,hotmail.com, ${ }^{1,2}$ felipe.antonele@gmail.com, \\ ${ }^{1,3}$ robson reis@hotmail.com.br, ${ }^{1,4}$ kaike12 amp@hotmail.com, ${ }^{1,5}$ netofalsin@hotmail.com, \\ 1,6 fabiodigrigoli@gmail.com e ${ }^{2}$ cleberwilliangomes@gmail.com
}

\section{RESUMO}

Em um mundo onde quase que a totalidade dos veículos automotores são movidos por motores à combustão interna e que as tendências mostram que estes motores terão uma parcela relevante até 2028 [1], os quais apresentam rendimento pouco atrativo, toda redução de perdas neste sistema é bem vinda [2].

Dentre as diversas fontes de perda de eficiência nos motores de combustão interna, a energia despendida para o meio ambiente através dos gases de escape é uma das que mais impactam no seu rendimento [2], a instalação de um Ciclo de Rankine Orgânico para recuperar parte dessa energia térmica desperdiçada é uma excelente alternativa para melhorar o desempenho de máquinas agrícolas, que operam por longos períodos com seus motores em plena carga, consumindo grande quantidade de combustível e emanando enorme quantidade de calor no ambiente.

A energia recuperada por este sistema pode ser convertida em energia elétrica e armazenada em baterias, podendo ser utilizada para alimentar um motor elétrico que forneça um incremento de torque ao trem de força da máquina agrícola, reduzindo-se assim o consumo de combustível e aumentando a força trativa.

Palavras-chave: Ciclo de Rankine Orgânico. Máquina agrícola. Recuperação energética. Sistema de exaustão.

\section{INTRODUÇÃO}

A queima da mistura combustível/ar presente na câmara de combustão de um veículo é uma reação exotérmica, ou seja, libera energia. Porém apenas uma parte desta energia é utilizada para promover a potência útil ao veículo, resultando um baixo rendimento energético ao motor. 
A baixa eficiência energética dos motores de combustão interna afeta quase que a totalidade da frota mundial. Segundo Antônio Domingues, 35\% da energia contida no combustível é liberada na forma de calor pelos gases de escape [2], conforme Figura 1.

Figura 1 - Distribuição de energia do motor

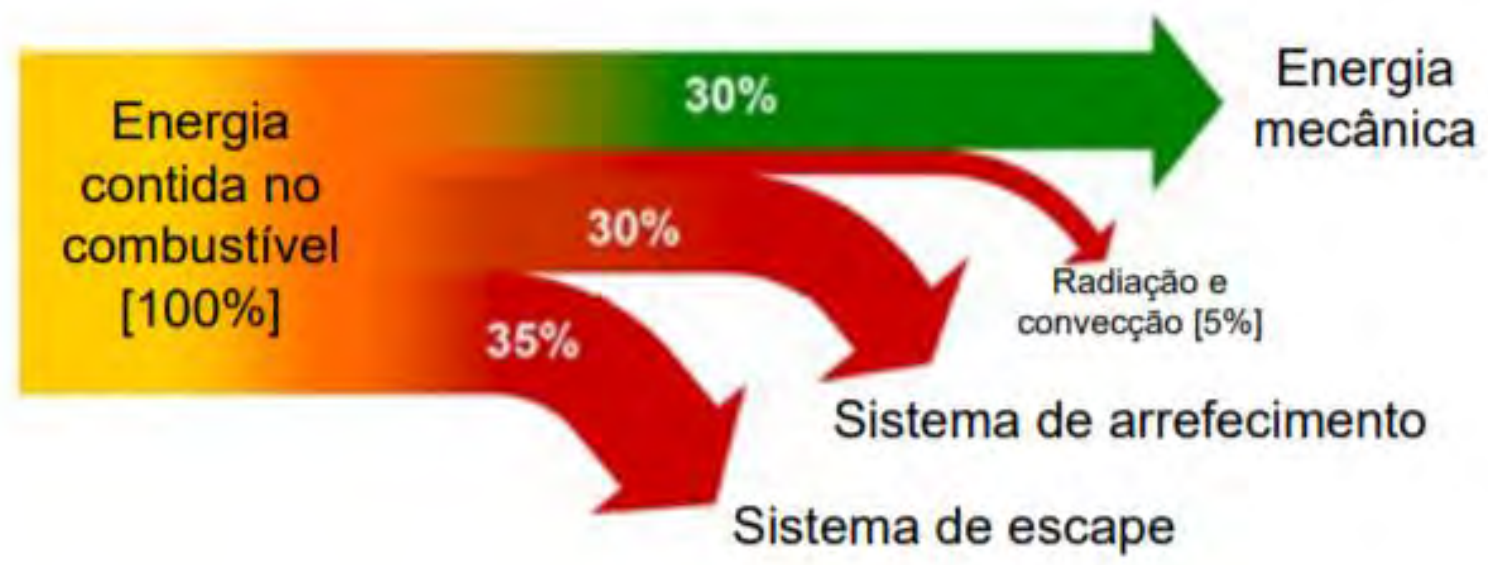

Fonte: DOMINGUES, Antônio [2].

Com o crescente aumento no preço dos combustíveis e as legislações cada vez mais rigorosas no controle da emissão de poluentes, é necessário que as indústrias invistam cada vez mais em tecnologias para que seus produtos sejam mais eficientes e seguros.

A proposta para a solução do problema é reaproveitar a energia térmica liberada pelos gases de escape, convertendo-a em energia elétrica, através de um sistema que usa o calor dos gases como fonte de energia, transformando parte da energia rejeitada em energia útil, assim aumentando a eficiência do motor.

Os sistemas de regeneração de energia atraem um interesse significativo dos responsáveis pelo desenvolvimento de novas tecnologias, uma vez que o potencial de recuperação de energia térmica dos motores é muito elevado.

A recuperação de energia útil na forma de eletricidade através dos gases de exaustão impacta diretamente na redução do consumo de combustível, aumentando a disponibilidade elétrica no sistema e melhorando sua eficiência através da adição de potência gerada ao motor.

\section{RECUPERAÇÃO ENERGÉTICA}

Diversos designs utilizados para recuperação energética dos gases de escape foram estudados, os princípios de funcionamento de cada modelo serão descritos a seguir juntamente com suas principais características.

\subsection{Gerador Termoelétrico}

Sistema capaz de gerar energia elétrica através da diferença de temperatura entre as faces de um material termoelétrico. O princípio de funcionamento é conhecido há bastante tempo e possui grande aplicação na fabricação de termopares, trata-se de um fenômeno conhecido como efeito Seebeck. O efeito Seebeck é capaz de gerar uma diferença de 
potencial entre duas junções de condutores de materiais diferentes em função da dilatação térmica de cada material quando estes são expostos a um gradiente térmico [3]. É o efeito inverso ao Peltier, que consiste na produção de um gradiente de temperatura através de um material quando uma diferença de potencial é aplicada.

Os fenômenos físicos por trás dos efeitos Seebeck e Peltier são a difusão de portadores de carga e o arrastamento fônon.

Figura 2 - Sistema de exaustão com gerador termoelétrico

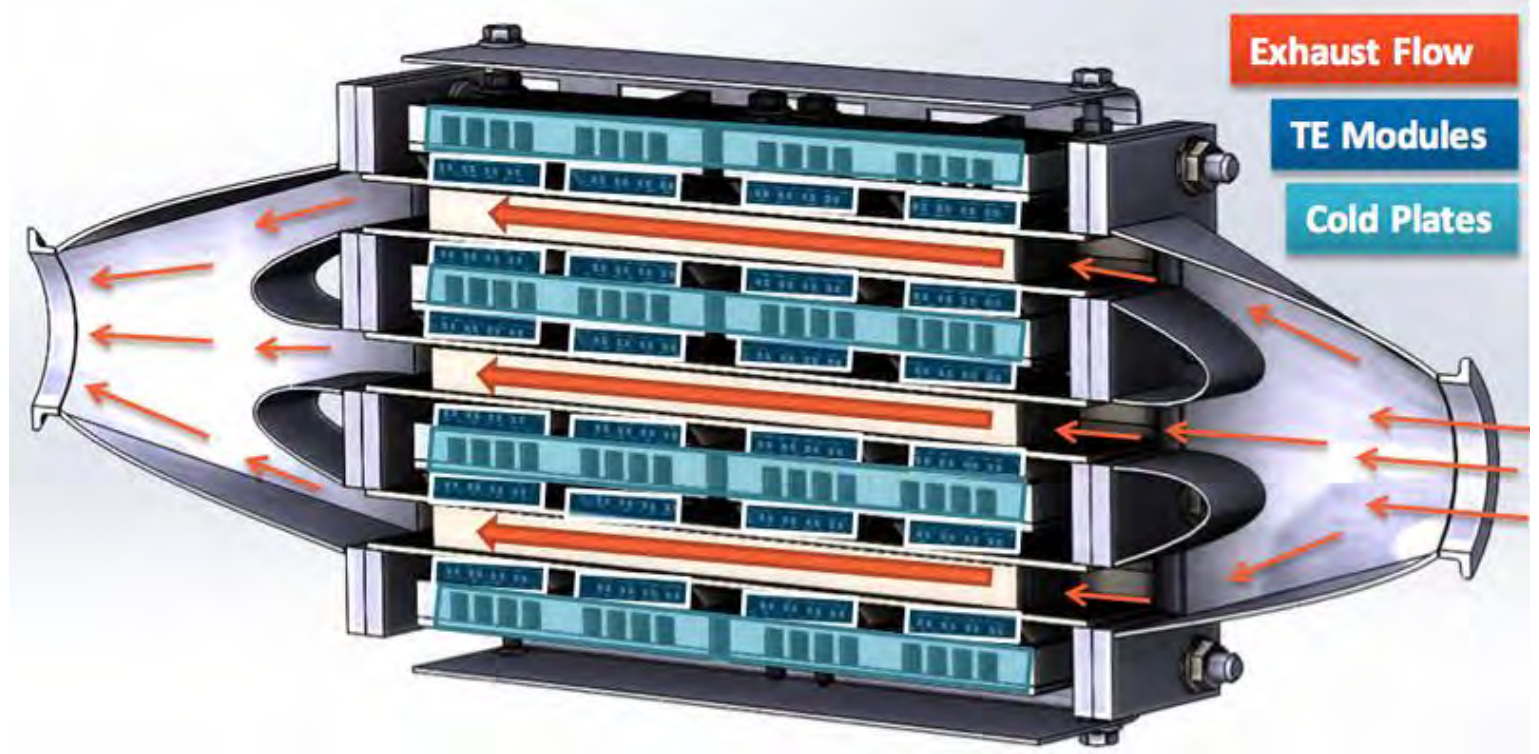

Fonte: Green Car Congress [4].

A principal vantagem deste modelo é a simplicidade do sistema, dispensando a necessidade de geradores elétricos e outros equipamentos complementares, a energia elétrica é extraída diretamente do conjunto de placas onde são instalados módulos de material termoelétrico. As placas são montadas de modo que em uma de suas faces circula o fluxo de gás de exaustão (lado quente) e na outra o fluido de arrefecimento (lado frio), o sistema pode ser instalado tanto na saída do coletor do motor a combustão interna, como no meio do tubo de escape do veículo.

Em contrapartida as desvantagens são o elevado custo dos módulos de material termoelétrico e a baixa densidade energética, que torna necessária a construção de placas de grandes dimensões e, consequentemente, de massa elevada para obter-se uma recuperação de energia considerável [5]. Apesar do crescente desenvolvimento de materiais para esta finalidade, os módulos comercialmente fornecidos apresentam rendimento muito baixo, tornando pouco viável a aplicação veicular deste modelo.

\subsection{Ciclo de Rankine}

Este sistema utiliza o ciclo térmico de Rankine para converter o calor dos gases de escape em energia mecânica, que pode ser convertida em elétrica através de um gerador ou ainda fornecer um incremento de torque diretamente no trem de força.

A energia térmica contida no sistema de exaustão é utilizada para aquecer, vaporizar e superaquecer um fluido de trabalho, o fluido vaporizado segue canalizado até a turbina, onde se expande, gerando potência de eixo. Um condensador instalado na saída da 
turbina retira calor do fluido reduzindo o seu título a zero e em seguida uma bomba se encarrega de recalcar o fluido de volta para o evaporador.

Os ciclos de Rankine se diferenciam pelo fluido de trabalho, podendo este ser água ou um fluido orgânico, sendo então classificados como Rankine Vapor e Rankine Orgânico, respectivamente. De acordo com Simone Lion, apesar do ciclo apresentar maior rendimento operando com água, este fluido se torna inviável para a aplicação veicular uma vez que dificilmente atingirá a condição de vapor superaquecido em função das temperaturas dos gases de escape em condições normais de operação do motor [6]. Por este motivo, o benchmarking para o ciclo de Rankine dispensa a água como fluido de trabalho, visto que as características de funcionamento são idênticas ao fluido orgânico e este apresenta melhor viabilidade técnica.

Figura 3 - Ciclo de Rankine instalado em um sistema de exaustão veicular

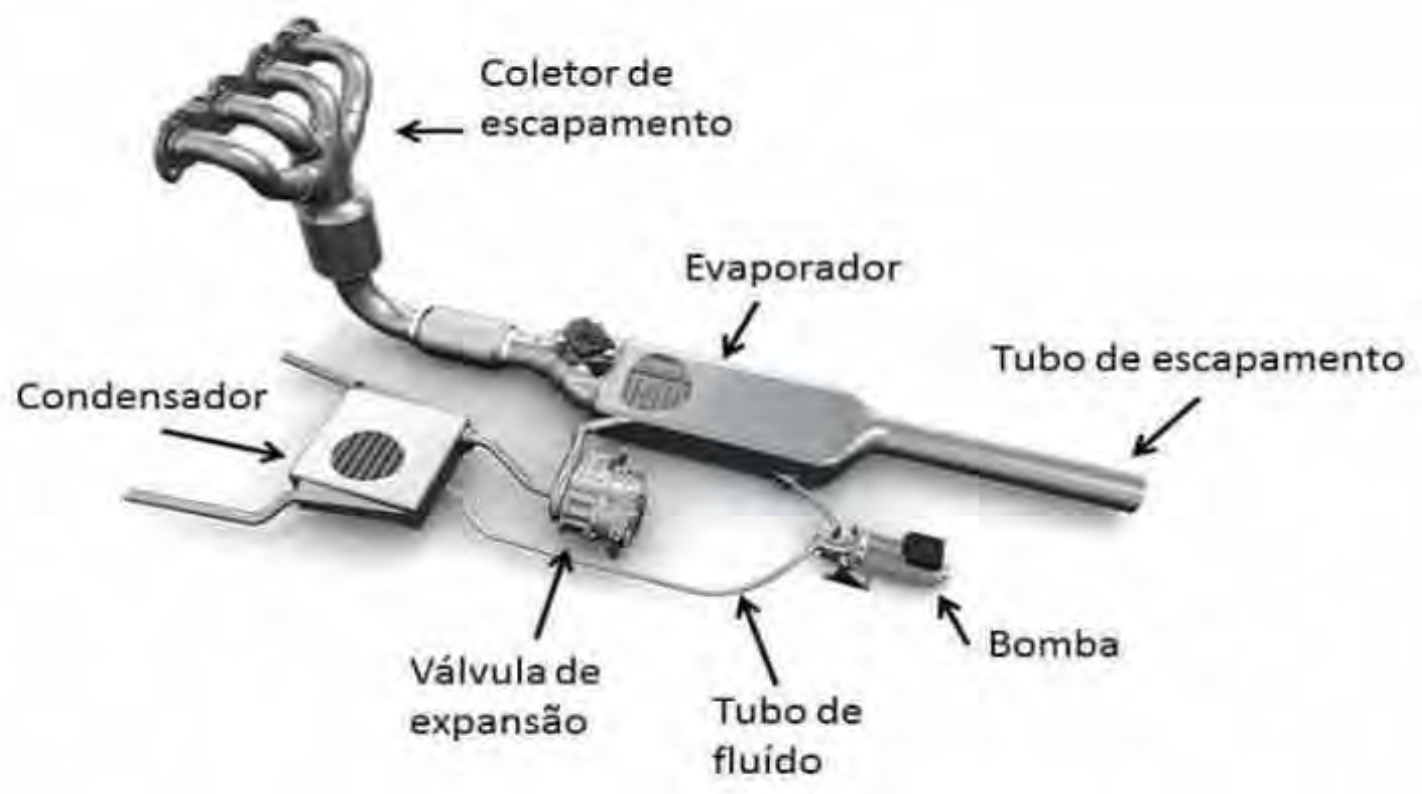

Fonte: AUTOentusiastas [7].

Neste modelo, diversos layouts podem ser configurados, incluindo sistemas de estágio simples ou duplo para circulação do fluido na fonte quente, apresentando diferentes resultados de rendimento e capacidade de geração [6].

A principal vantagem deste design é a alta capacidade de recuperação energética, sendo capaz de reaproveitar boa parte da energia despendida através dos gases de escape, porém a grande quantidade de componentes o torna um sistema complexo e requer espaço para instalação.

\subsection{Turbogerador Elétrico}

Outro modelo disponível no mercado com a finalidade de recuperar energia dos gases de escape é o turbogerador, este sistema não aproveita a energia térmica contida nos gases, mas sim a energia cinética destes. Um motor de combustão interna em operação lança na atmosfera uma enorme quantidade de gases queimados em alta velocidade, o escoamento dos gases através do conduto do sistema de exaustão é capaz de fornecer potência suficiente para girar uma turbina, a energia mecânica extraída da turbina pode ser 
utilizada para gerar energia elétrica através de um gerador, assim como no ciclo de Rankine.

A potência fornecida à turbina é diretamente proporcional a rotação do motor, visto que quanto maior a rotação, maior será o volume de gases queimados por unidade de tempo dispensados através do sistema de escape. Desta forma a potência recuperada varia muito em função das condições de operação do veículo automotor, o que acaba sendo uma desvantagem para este sistema [8].

Outra desvantagem é a contrapressão imposta pela instalação da turbina no duto do escapamento, que reduz a área de escoamento dificultando a passagem dos gases, causando perda de potência no motor e reduzindo seu rendimento.

A vantagem fica por conta da simplicidade de instalação, que possui poucos componentes, sendo um sistema compacto e leve.

Figura 4 - Turbogerador

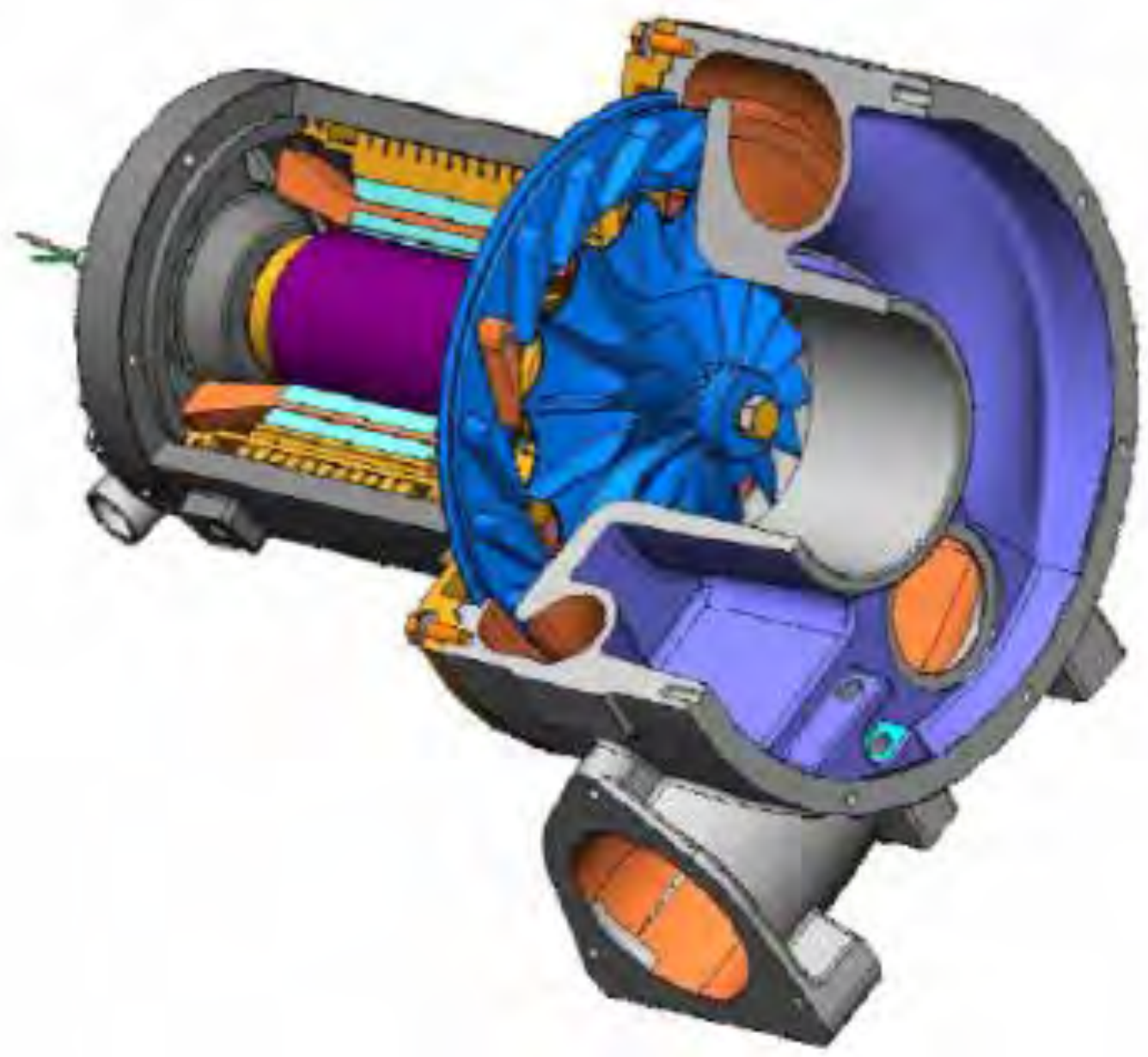

Fonte: Celiça Supra [9]. 


\subsection{Motor Stirling}

O motor Stirling é um motor de combustão externa, nele um gás confinado em uma câmara é aquecido por uma fonte externa de calor, expandindo-se e promovendo o deslocamento de um pistão. O sistema trabalha com dois pistões interligados cinematicamente de modo que enquanto um avança o outro recua, comprimindo um gás confinado em outra câmara. As duas câmaras são interligadas, de modo que o gás comprimido contido na câmara fria passe para a câmara quente resfriando o gás expandido, gerando trabalho através dos ciclos de expansão e compressão do gás confinado.

Assim como o ciclo de Rankine, o motor Stirling também converte a energia térmica contida nos gases de escape em energia mecânica, podendo esta ser aproveitada para gerar energia elétrica através de um gerador.

Figura 5 - Motor Stirling

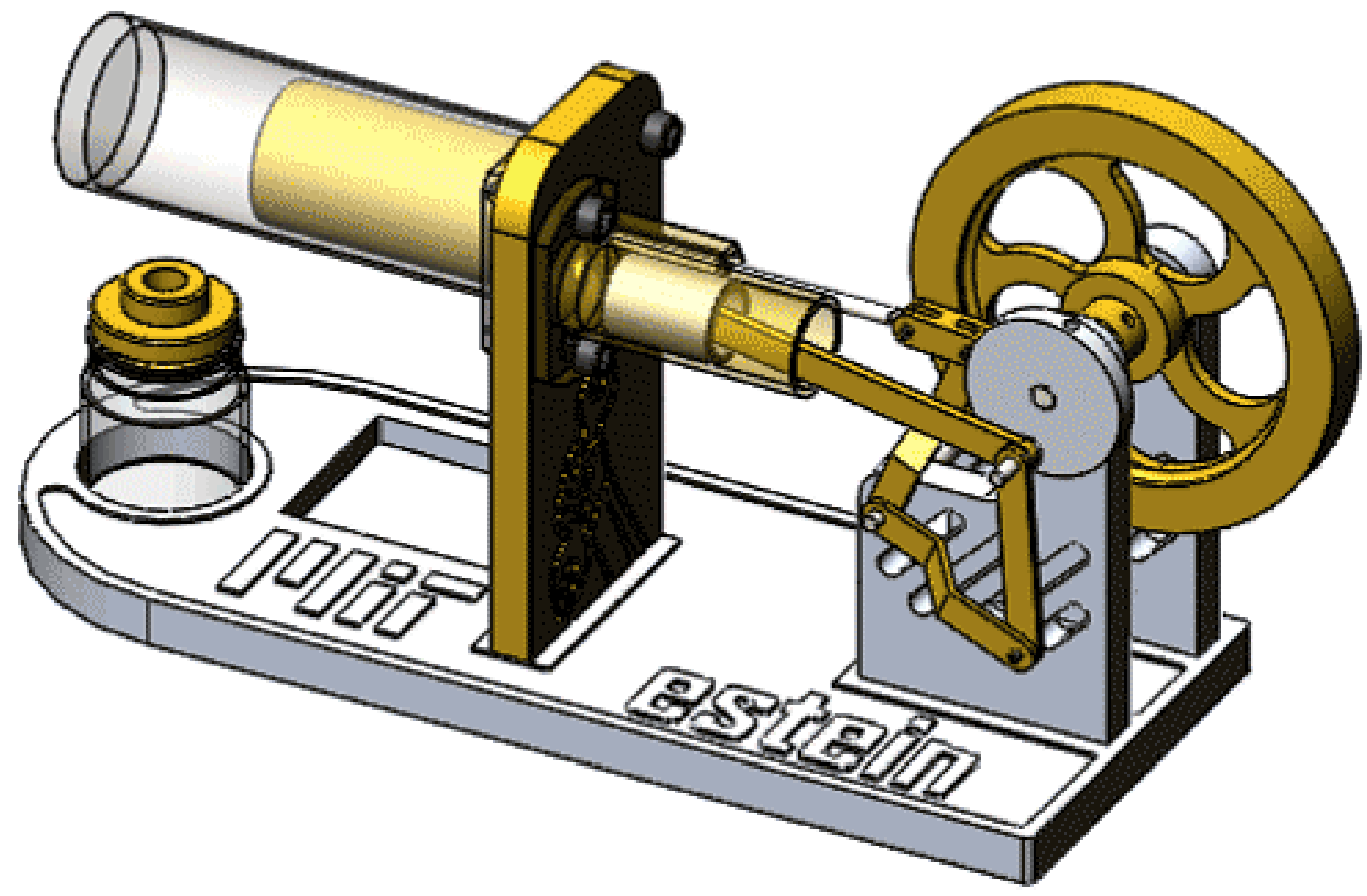

Fonte: Emma Steinhardt [10].

Apesar de ser um sistema simples e de fácil manutenção, o motor de combustão externa apresenta baixa densidade de potência, o que significa que é necessário um equipamento de grandes dimensões e massa elevada para se obter uma recuperação energética considerável [11], o que limita bastante sua aplicação no ramo automotivo.

\subsection{Matriz de Decisão}

Para definir os critérios de avaliação que fundamentam melhor a escolha, optou-se por listar as características que, do ponto de vista do consumidor final, são mais relevantes, de modo a atribuir maior valor percebido ao produto, uma vez que a implementação do 
sistema de recuperação de energia agrega maior custo de fabricação e maior complexidade ao veículo, exigindo maior necessidade de manutenção.

Desta forma, os critérios de avaliação escolhidos para comparação dos designs na matriz de decisão foram:

- Capacidade de recuperação energética;

- Redução no consumo de combustível;

- Facilidade na instalação;

- Potencial frequência de manutenção;

- Complexidade do sistema.

\subsubsection{Escala de avaliação}

A escala de avaliação fundamentou-se na comparação dos modelos selecionados como benchmarkings com o veículo atual de mercado, o qual não possui nenhum sistema de recuperação de energia dos gases de escape.

A comparação fundamentou-se através da seguinte escala:

- Sem alteração (indiferença entre o sistema atual com o sistema proposto para o critério avaliado, atribuindo-se o sinal "x");

- Melhor (o sistema proposto se sobressai ante ao sistema atual para o critério avaliado, atribuindo-se o sinal "+");

- Pior (o sistema atual se sobressai ante ao sistema proposto para o critério avaliado, atribuindo-se o sinal “-”).

\subsubsection{Tabela de comparação}

Tomando-se os critérios e a escala de avaliação, os quatro modelos foram listados em uma tabela de modo a serem comparados individualmente com o veículo atual sem sistema de recuperação energética. Prevalecendo aquele que somar maior quantidade de sinais "+", o sistema selecionado como a melhor alternativa para a solução do problema apresentado foi o Ciclo de Rankine Orgânico, conforme Tabela 1, em função de sua alta capacidade de recuperação energética e consequente redução no consumo de combustível. 
Tabela 1 - Matriz de decisão

\begin{tabular}{|c|c|c|c|c|c|}
\hline & Sistema Atual & $\begin{array}{c}\text { Gerador } \\
\text { Termoelétrico }\end{array}$ & $\begin{array}{c}\text { Turbo Gerador } \\
\text { Elétrico }\end{array}$ & $\begin{array}{c}\text { Ciclo de } \\
\text { Rankine } \\
\text { Orgânico }\end{array}$ & $\begin{array}{c}\text { Motor } \\
\text { Stirling }\end{array}$ \\
\hline $\begin{array}{c}\text { Recuperação } \\
\text { Energética }\end{array}$ & $\mathbf{X}$ & + & ++ & +++ & ++ \\
\hline $\begin{array}{c}\text { Redução no } \\
\text { Consumo do } \\
\text { Combustivel }\end{array}$ & $\mathbf{X}$ & ++ & + & +++ & ++ \\
\hline $\begin{array}{c}\text { Facilidade de } \\
\text { Instalação }\end{array}$ & $\mathbf{X}$ & - & -- & - & -- \\
\hline $\begin{array}{c}\text { Manutenção } \\
\text { Complexidade } \\
\text { do Sistema }\end{array}$ & $\mathbf{X}$ & - & - & -- & -- \\
\hline $\begin{array}{c}\text { Total } \\
\text { S Sem Alteração }\end{array}$ & $\mathbf{X}$ & - & - & -- & -- \\
\hline
\end{tabular}

Fonte: Autores.

\section{CICLO DE RANKINE ORGÂNICO}

Descoberto e nomeado por William John Macquorn Rankine, um escocês polímata e professor da Universidade de Glasgow na década de 1840 [12], o ciclo termodinâmico Rankine representa de forma idealizada o funcionamento das máquinas a vapor, que transformam energia térmica em mecânica através dos ciclos de compressão e expansão do fluido de trabalho quando em transição de fase [13].

O ciclo Rankine baseia-se em quatro processos termodinâmicos. Compressão e expansão isentrópicas e fornecimento e rejeição de calor isobáricos, conforme indicado no diagrama de temperatura versus entropia específica, como mostra a Figura 6. 


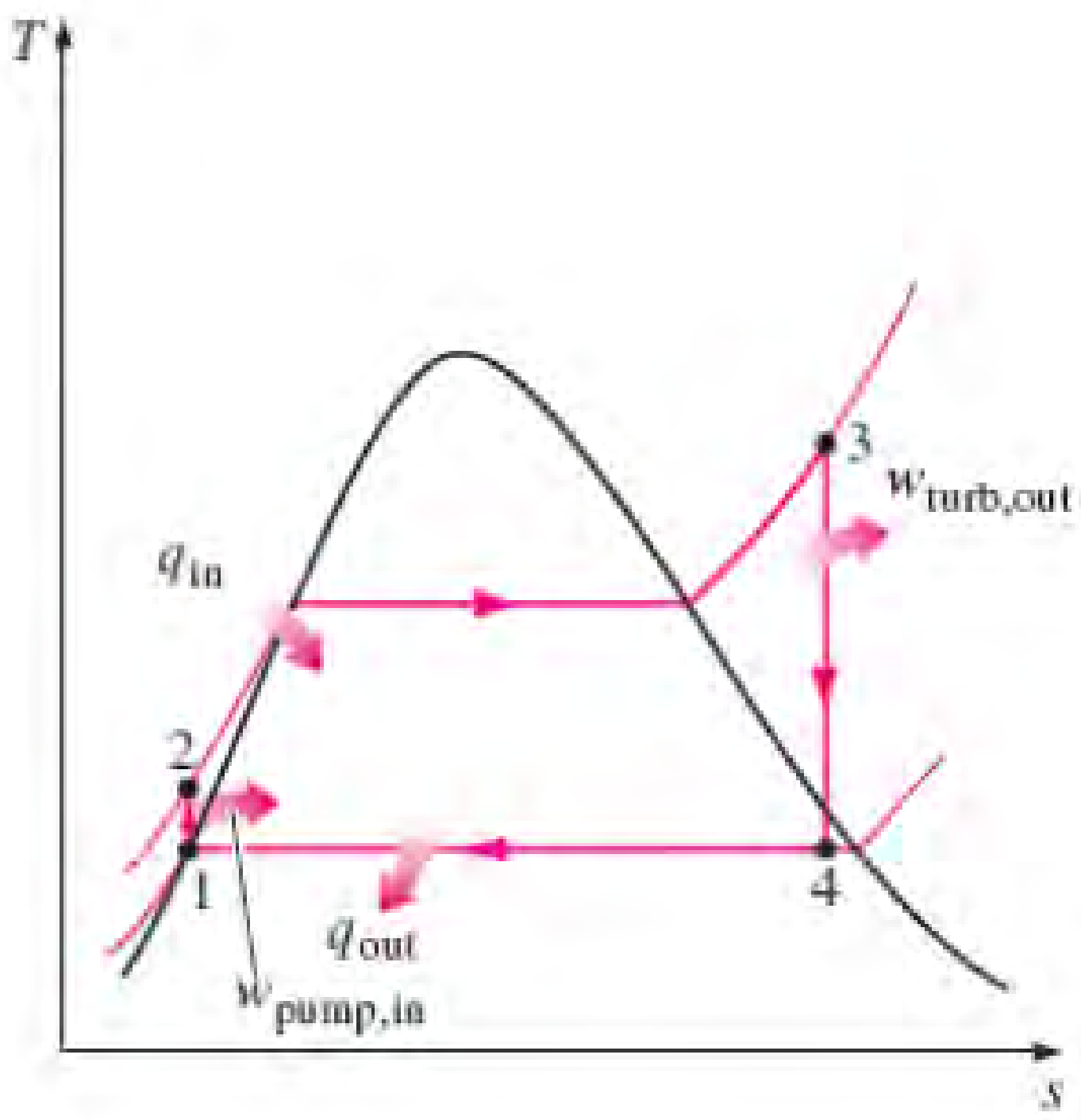

Fonte: ÇENGEL, Yunus [14].

Desta maneira, os processos que compõe o ciclo de Rankine são:

- 1-2: Compressão isentrópica do líquido saturado (bomba);

- 2-3: Fornecimento de calor a pressão constante (caldeira);

- 3-4: Expansão isentrópica do vapor superaquecido (turbina);

- 4-1: Rejeição de calor a pressão constante (condensador).

O ciclo orgânico de Rankine (ORC - Organic Rankine Cycle) é baseado no ciclo a vapor de Rankine (SRC - Steam Rankine Cycle) onde o objetivo é obter trabalho gerado pela movimentação do gás superaquecido através da turbina geradora do sistema, após isso o fluido é refrigerado passando pelo condensador, transferido para a bomba, então novamente para o elemento de aquecimento e retorna à turbina para realizar um novo ciclo de trabalho, conforme Figura 7. 
A vantagem em relação ao ciclo Rankine Vapor está no fato de que o fluido orgânico é capaz de ser superaquecido a temperaturas superiores a temperatura de evaporação da água, absorvendo e liberando mais energia durante ciclo de trabalho para a turbina.

Figura 7 - Representação esquemática do ciclo de Rankine orgânico

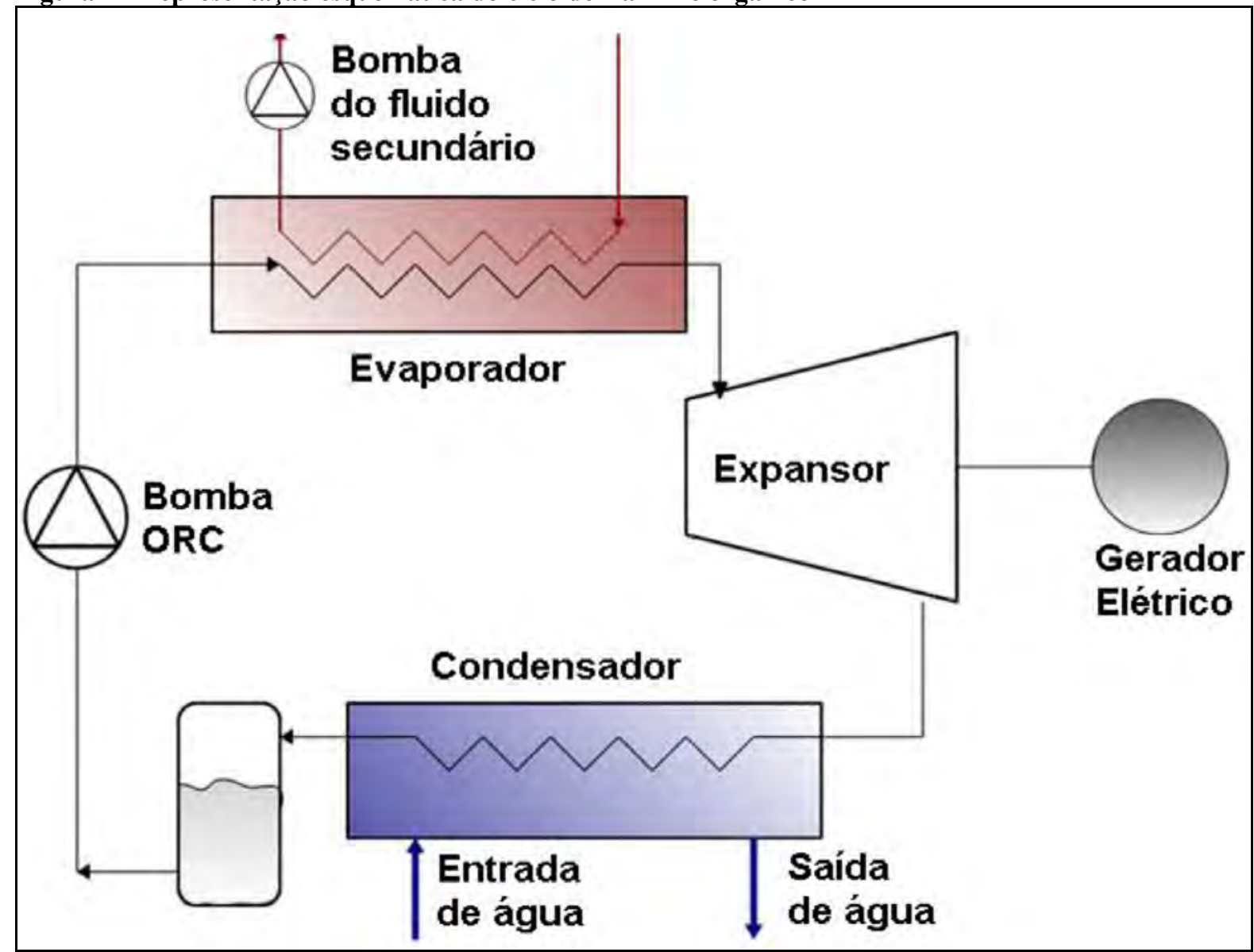

Fonte: WENZEL, Thiago [15].

\subsection{Aplicação do sistema}

Por se tratar de um sistema de grandes dimensões e elevada massa, a aplicação do ciclo de Rankine Orgânico como fonte de recuperação energética do calor dos gases de escape é mais indicada para veículos de grande porte. Além disso, outras características devem ser consideradas, como a faixa de rotação e carga de operação do motor, pois quanto maiores a temperatura e vazão dos gases, maior o potencial de recuperação energética.

Estudando-se as características operacionais de diversos veículos de grande porte, obtevese a distribuição da faixa de rotação e carga de operação que predomina em cada tipo de veículo, conforme observa-se na Figura 8. 
Figura 8 - Veículos e suas características operacionais
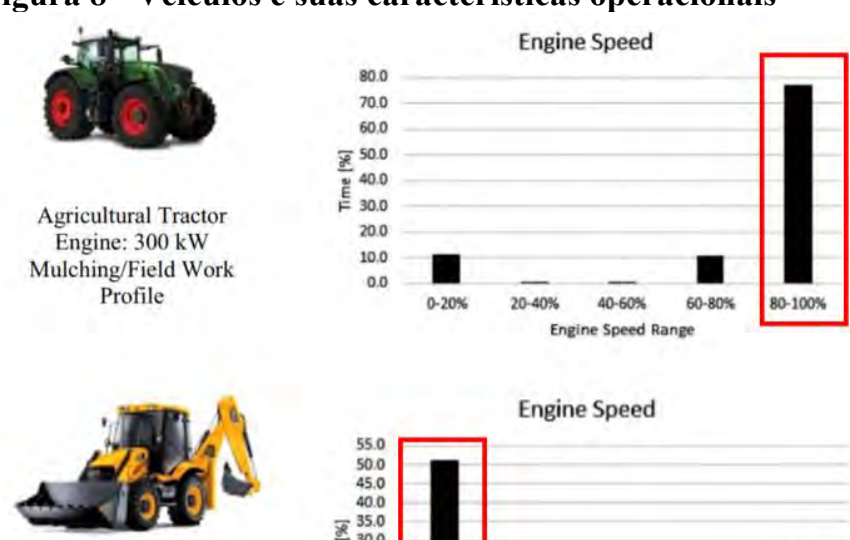

Backhoe Loader Engine Power Range: 50 . $100 \mathrm{~kW}$

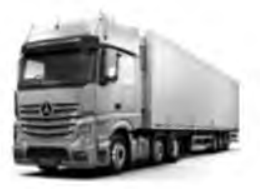

Long-haul Truck Engine: $350 \mathrm{~kW}$ City Profile

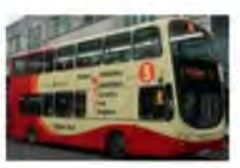

City Line Bus Engine: $190 \mathrm{~kW} \mathrm{Eu} \mathrm{V}$ (DOC+DPF+SCR)

City Line Profile
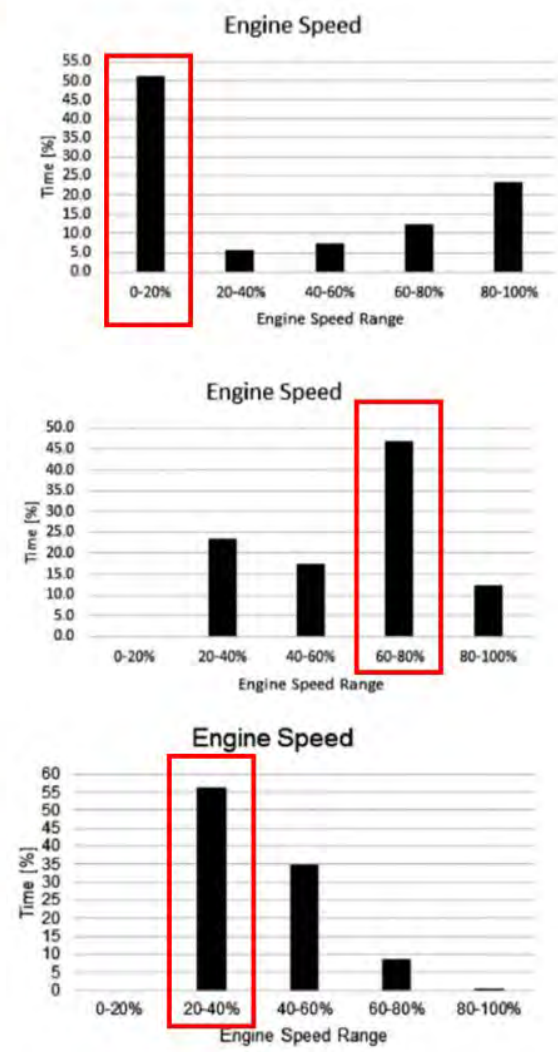
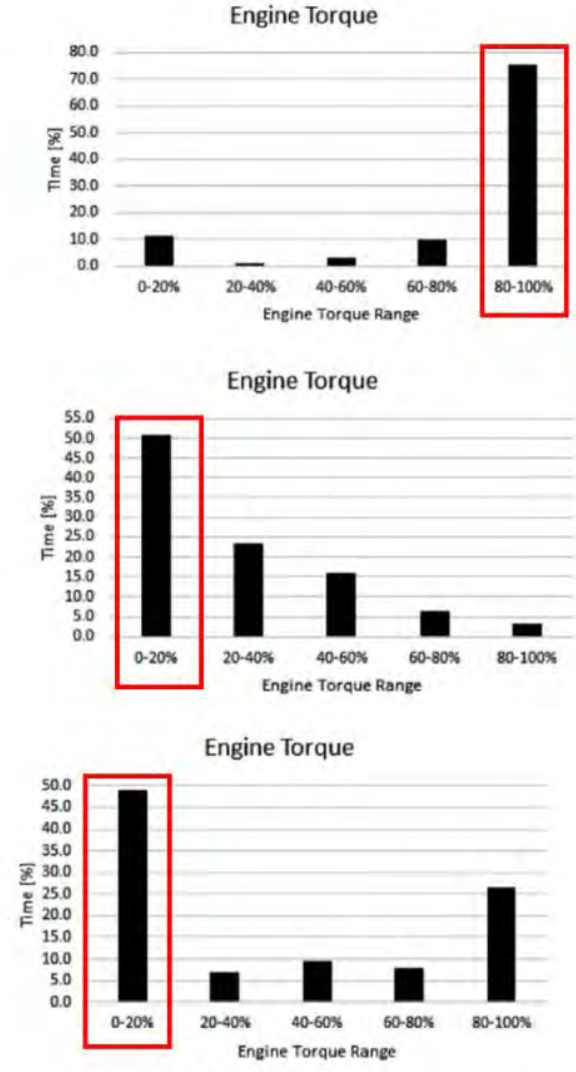

Engine Torque

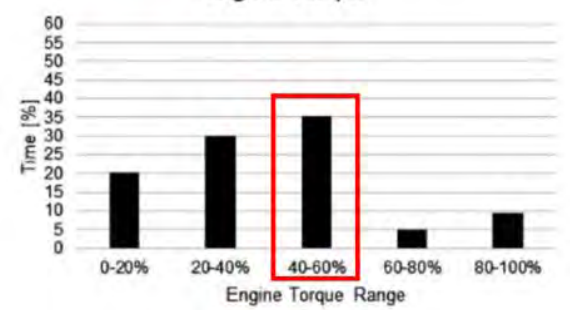

Fonte: Adaptado de LION, Simone; MICHOS, Constantine N.; VLASKOS, Ioannis; TACCANI, Rodolfo [16].

Com base nesse estudo, concluiu-se que o sistema proposto é melhor aproveitado quando instalado em máquinas agrícolas, e função de sua operação quase sempre em carga máxima e alta rotação do motor. Além disso, o aumento de massa provocado pela instalação deste sistema adicional pode tornar-se um benefício, uma vez que o aumento de massa pode aumentar a capacidade trativa da máquina agrícola.

A grande maioria dos estudos relacionados a ciclos de Rankine orgânico exploram mais as aplicações de veículos para passageiros, de estrada (caminhões), aplicações estacionárias de geração de energia, veículos marítimos entre outros, deixando as máquinas agrícolas fora de estrada menos exploradas no ramo da recuperação energética, evidenciando a oportunidade da exploração deste segmento.

\subsection{Package da Aplicação}

Com o intuito de avaliar as oportunidades e estudar o espaço disponível para a instalação do sistema, denominado Package da aplicação, foi desenvolvido um Sketch 
demonstrando as posições dos componentes do ciclo de Rankine desde a recuperação energética até a conexão do motor auxiliar elétrico nas rodas traseiras do veículo, com o objetivo de reduzir o consumo da potência gerada pelo motor a diesel, como mostra a Figura 9.

Figura 9 - Modelo Simplificado

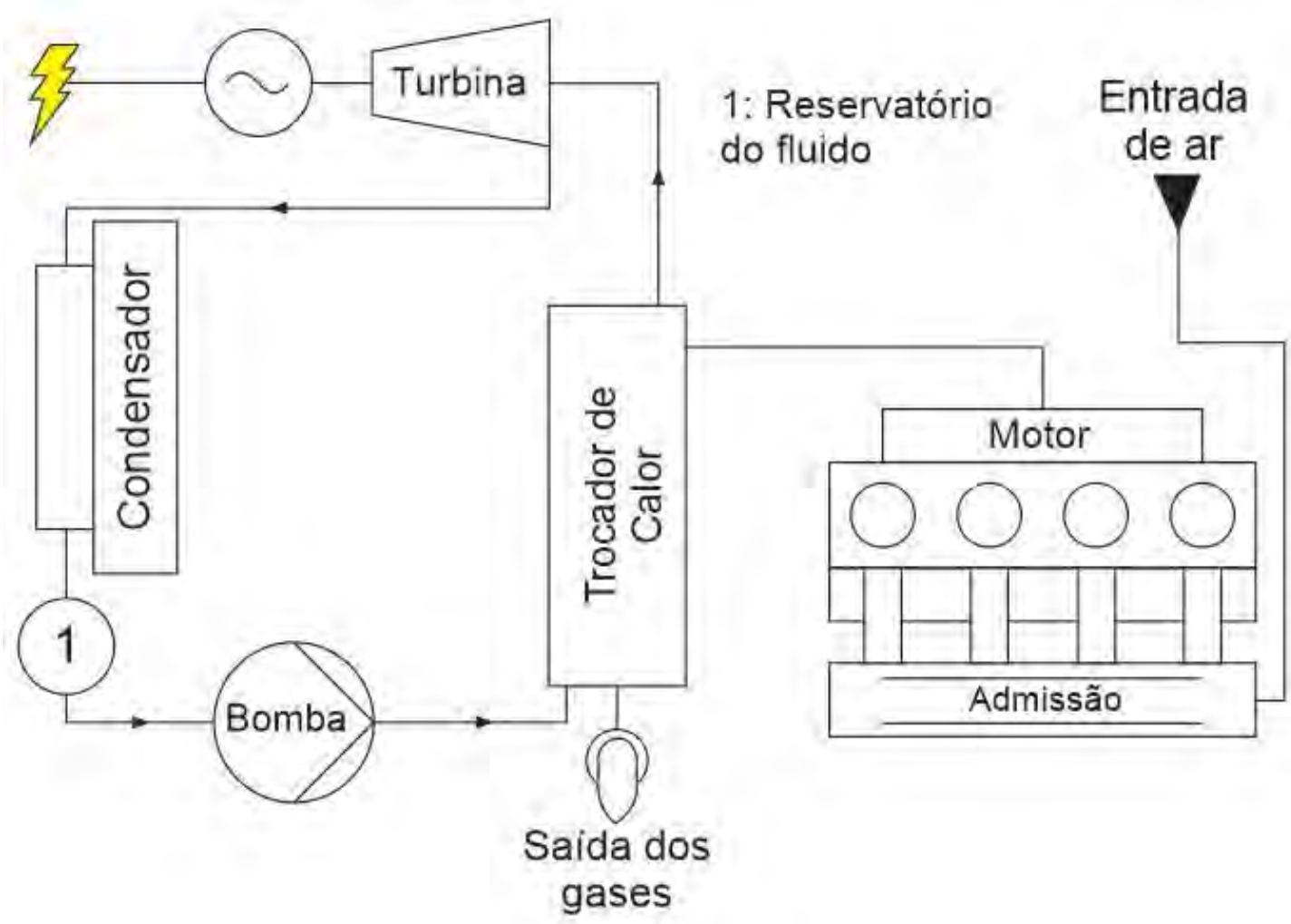

Fonte: Autores.

Para analisar o espaço disponível, foi selecionada a máquina da New Holland, modelo T8020, da qual foram levantadas as características dimensionais conforme abaixo [17], a fim de definir o package 3D do sistema, de acordo com a Figura 10.

- Carga máxima: $13381 \mathrm{~kg}$;

- Distância entre eixos: 3,07m;

- Comprimento: 5,82m;

- Largura: 2,48m;

- Altura: 3,32m. 
Figura 10 - Disposição dos componentes do sistema no veículo

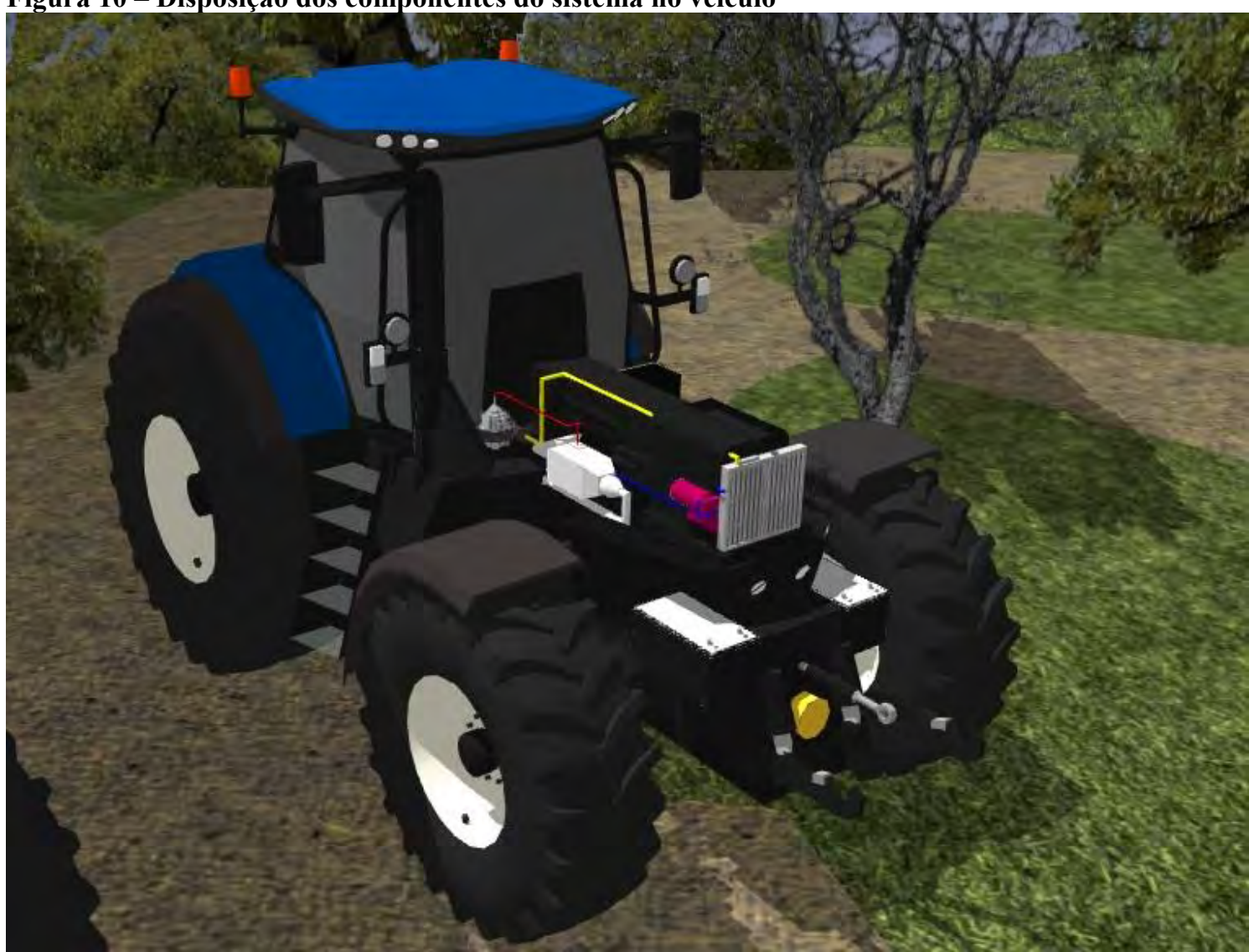

Fonte: Autores.

Levantou-se também as principais características do motor que a equipa [18], sendo um motor Diesel da Cummins 6CTAA8.3-C280 de 6 cilindros em linha, com as seguintes características:

- Potência máxima em bancada: 206 kW@2200 rpm;

- Faixa de Rotação: 1000 2200 rpm.

\section{PROCESSO DE DESENVOLVIMENTO DO SISTEMA}

Foram utilizados os softwares AVL Boost ${ }^{\mathrm{TM}}$ e EES $^{\circledR}$ (Engineering Equation Solver), para o cálculo da melhoria proposta, conforme descrito a seguir.

\subsection{Simulação no AVL Boost ${ }^{\mathrm{TM}}$}

Com o auxílio do software AVL Boost ${ }^{\mathrm{TM}}$ foram levantadas as curvas características do motor, conforme Figura 11, utilizando como entrada as dimensões dos cilindros, a pressão de trabalho da turbina, a taxa de compressão do motor, a curva de combustão, a temperatura e pressão do ar atmosférico, as dimensões do intercooler e o sistema de tratamento dos gases de escape, obtendo-se os dados dos gases de escape, como pressão, temperatura e vazão mássica, conforme indicado na Tabela 2. 
Figura 11 - Layout do motor simulado no AVL Boost ${ }^{\text {TM }}$

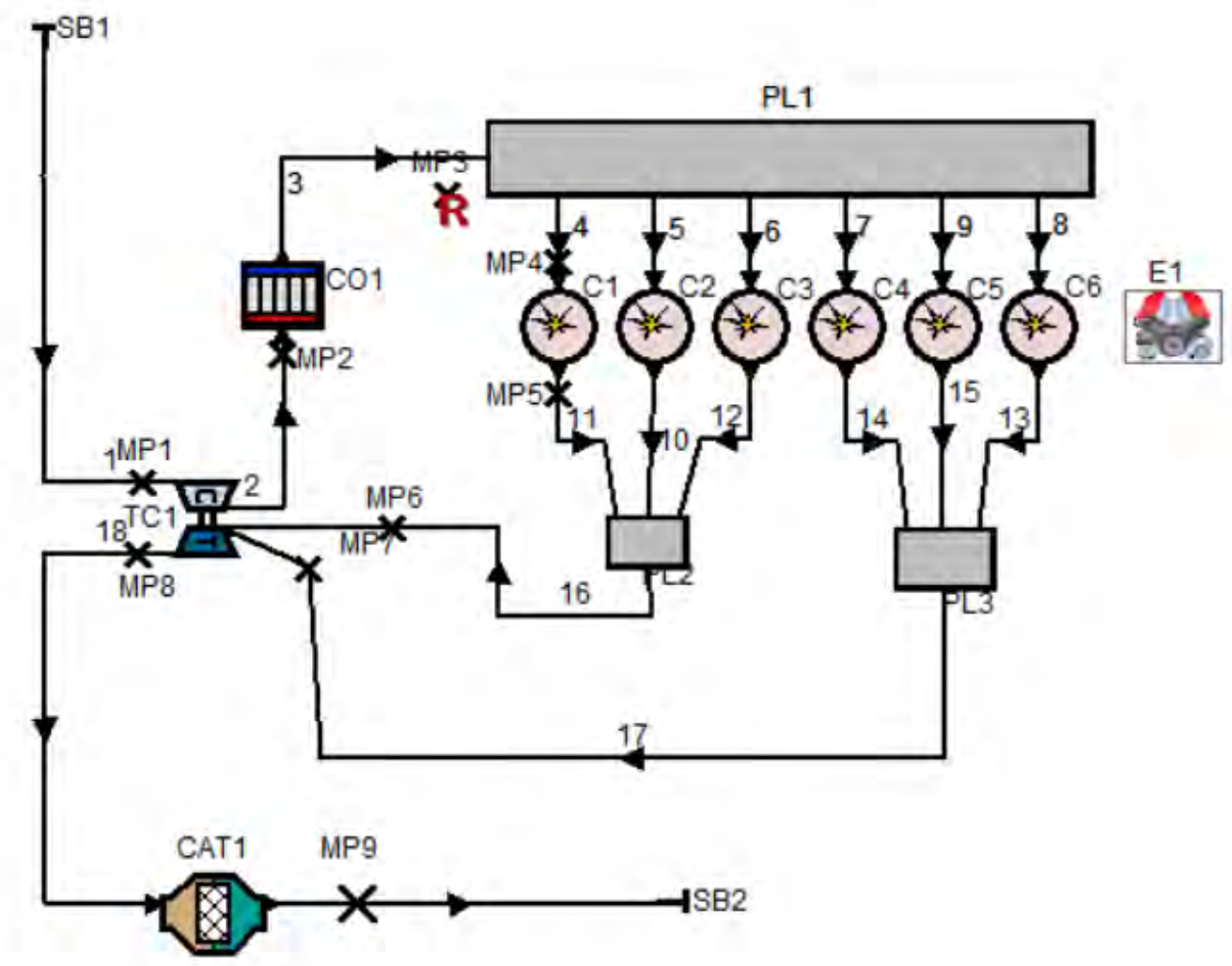

Fonte: Autores.

Tabela 2 - Dados extraídos do AVL Boost ${ }^{\mathrm{TM}}$

\begin{tabular}{|c|c|c|c|c|}
\hline \multicolumn{5}{|c|}{ AVL } \\
\hline Rotação & Pressão & Temperatura gás de escape & Velocidade & Vazão em massa \\
\hline [rpm] & {$[\mathrm{Pa}]$} & {$[\stackrel{\circ}{ }]$} & {$[\mathrm{m} / \mathrm{s}]$} & {$[\mathrm{kg} / \mathrm{s}]$} \\
\hline 800 & 110500 & 463,1 & 52,4 & 0,1554 \\
\hline 1000 & 11030 & 483,8 & 67,7 & 0,1949 \\
\hline 1200 & 110280 & 494 & 82,8 & 0,2355 \\
\hline 1400 & 110400 & 514,3 & 99,5 & 0,276 \\
\hline 1600 & 110530 & 526 & 116,8 & 0,3194 \\
\hline 1800 & 110680 & 535,2 & 132,5 & 0,3587 \\
\hline 2000 & 110850 & 543,1 & 146,5 & 0,3935 \\
\hline 2200 & 110980 & 550,2 & 158,4 & 0,4222 \\
\hline
\end{tabular}

Fonte: Autores.

\subsection{Simulação no $\mathrm{EES}^{\circledR}$}

Com os dados levantados pelo AVL Boost ${ }^{\mathrm{TM}}$, foi possível calcular através do software EES $^{\circledR}$ as dimensões e os parâmetros dos componentes do sistema, dispondo de uma série de equações da termodinâmica [14] e transmissão de calor [19], utilizando como entrada 
a geometria dos trocados de calor, a temperatura de saída e vazão mássica dos gases de escape e as propriedades termodinâmicas de diversos fluidos, objetivando o maior potencial de recuperação energética.

\subsubsection{Bomba}

A bomba fornece energia ao fluido, aumentando sua pressão, a função principal deste componente é recalcar o fluido de trabalho para dentro da caldeira, consumindo, geralmente, parte da energia gerada pelo próprio ciclo para este fim, representando assim, um trabalho negativo dentro do sistema.

O trabalho consumido pela bomba pode ser obtido através da seguinte equação [14]:

$$
W_{B}=h_{2}-h_{1}=v\left(p_{2}-p_{1}\right)=W_{e}
$$

Onde:

$\mathrm{W}_{\mathrm{B}}$ : Trabalho da bomba;

$\mathrm{h}_{2}$ : Entalpia específica na saída da bomba;

$\mathrm{h}_{1}$ : Entalpia específica na entrada da bomba;

$\mathrm{v}$ : Volume específico;

$\mathrm{p}_{2}$ : Pressão na saída da bomba;

$\mathrm{p}_{1}$ : Pressão na entrada da bomba.

$\mathrm{W}_{\mathrm{e}}$ : Trabalho que entra no sistema;

Note que, além da variação de entalpia específica, o trabalho da bomba também pode ser obtido através do produto do volume específico com a variação de pressão do fluido de trabalho recalcado.

\subsubsection{Caldeira}

O calor que entra na caldeira é a pricipal fonte de energia do sistema. Neste componente ocorre a vaporização e superaquecimento do fluido a pressão constante. A temperatura de saída da caldeira $T_{3}$ deve respeitar a temperatura crítica do fluido de trabalho, que é a temperatura a partir da qual o fluido degrada termicamente, devendo ser alta o suficiente para garantir um bom rendimento do ciclo térmico.

O calor fornecido para a caldeira pode ser expresso através da variação de entalpia específica, conforme equação [19]:

$$
q_{\text {cald }}=h_{3}-h_{2}=q_{e}
$$

Onde:

qcald: Troca de calor na caldeira;

$\mathrm{h}_{3}$ : Entalpia específica na saída da caldeira;

$\mathrm{h}_{2}$ : Entalpia específica na entrada da caldeira;

$\mathrm{q}_{\mathrm{e}}$ : Calor que entra no sistema. 


\subsubsection{Turbina}

A turbina, ou expansor, é o componente responsável pela conversão da energia térmica em mecânica. Nela o vapor superaquecido se expande, promovendo a movimentação de um rotor de onde extrai-se a potência, que é o produto do torque pela rotação do rotor.

O trabalho realizado na turbina pode ser equacionado por [14]:

$$
W_{T}=h_{3}-h_{4}=W_{S}
$$

Onde:

$\mathrm{W}_{\mathrm{T}}$ : Trabalho da turbina;

$\mathrm{h}_{3}$ : Entalpia específica na entrada da turbina;

$\mathrm{h}_{4}$ : Entalpia específica na saída da turbina;

$\mathrm{W}_{\mathrm{s}}$ : Trabalho que sai do sistema.

A expansão do fluido reduz o seu título, liberando uma mistura líquido-vapor na exaustão, podendo causar a erosão deste componente, para evitar que isto ocorra, recomenda-se que o título na saída da turbina seja maior ou igual a $85 \%$.

\subsubsection{Condensador}

No condensador a mistura é tranformada novamente para o estado líquido para evitar a ocorrência de cavitação na bomba. Neste processo o calor é retirado do fluido a pressão constante até que se atinja a titulação zero.

O calor removido no condensador pode ser expresso através da equação a seguir [19]:

$$
q_{\text {cond }}=h_{4}-h_{1}=q_{s}
$$

Onde:

qcond: Calor rejeitado pelo condensador;

h4: Entalpia específica na entrada do condensador;

$\mathrm{h}_{1}$ : Entalpia específica na saída do condensador;

$\mathrm{q}_{\mathrm{s}}$ : Calor que saí do sistema.

\subsubsection{Eficiência térmica}

A eficiência térmica do ciclo de Rankine pode ser mensurada através da relação do trabalho gerado na turbina pelo calor fornecido à caldeira, descontando-se o trabalho fornecido para a bomba. Desta maneira obtém-se a expressão:

$$
\eta=\frac{W_{T}-W_{B}}{q_{\text {Cald }}}=\frac{W_{s}-W_{e}}{q_{e}}
$$


Onde:

$\eta$ : Rendimento do ciclo;

$\mathrm{W}_{\mathrm{T}}$ : Trabalho da turbina;

$\mathrm{W}_{\mathrm{B}}$ : Trabalho da bomba;

$\mathrm{q}_{\text {cald: }}$ Troca de calor na caldeira;

$\mathrm{W}_{\mathrm{s}}$ : Trabalho que sai do sistema.

$\mathrm{W}_{\mathrm{e}}$ : Trabalho que entra no sistema;

qe: Calor que entra no sistema.

A eficiência térmica do ciclo de Rankine pode ser majorada basicamente de duas maneiras. Aumentando a temperatura média na qual o calor é transferido para o fluido de trabalho na caldeira ou diminuindo a temperatura na qual o calor é rejeitado do fluido de trabalho no condensador.

\section{RESULTADOS}

A partir do dimensionamento realizado no software EES, levantou-se para o Tolueno, fluido que apresentou o maior potencial de recuperação energética, um gráfico da transmissão de calor na caldeira e no condensador em função da rotação do motor, conforme observa-se Figura 12.

Figura 12 - Transmissão de calor na caldeira e no condensador

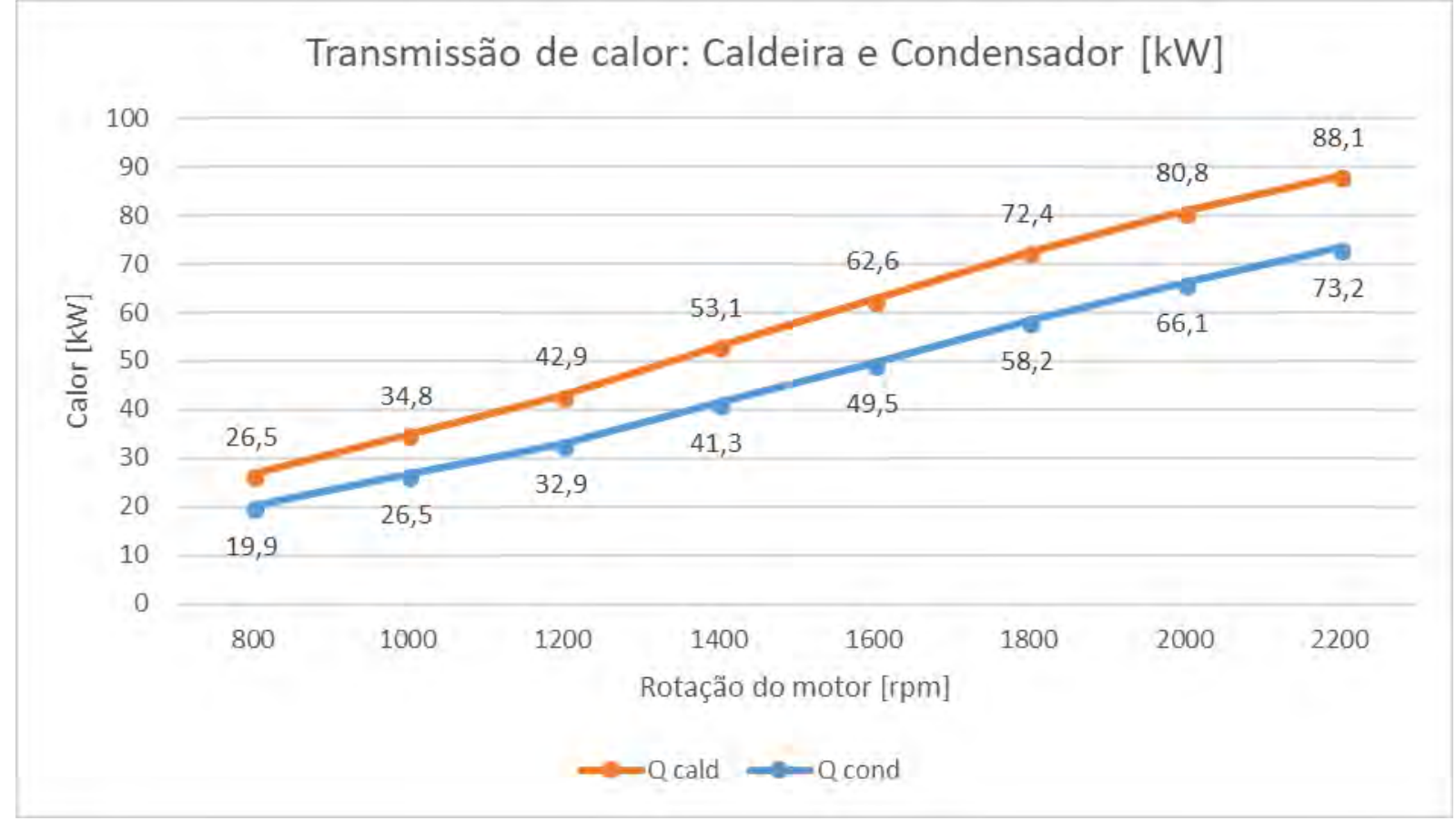

Fonte: Autores.

Um gráfico da potência útil regenerada em função da rotação do motor também foi extraído do mesmo dimensionamento, de acordo com a Figura 13. 
Figura 13 - Potência útil recuperada

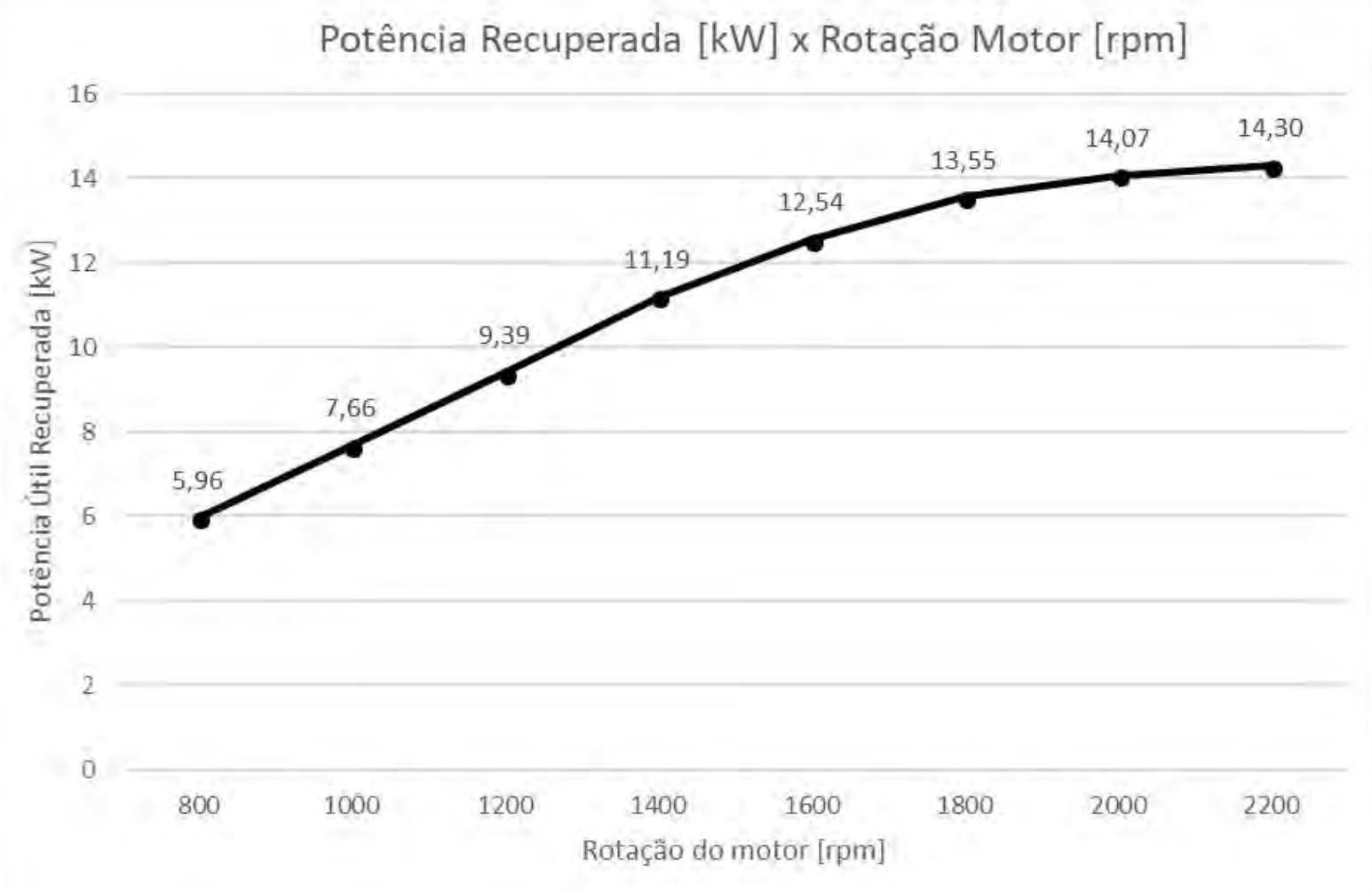

Fonte: Autores.

Por fim, um gráfico do rendimento do ciclo foi elaborado também em função da rotação do motor, conforme indicado na Figura 14. 
Figura 14 - Rendimento do ciclo

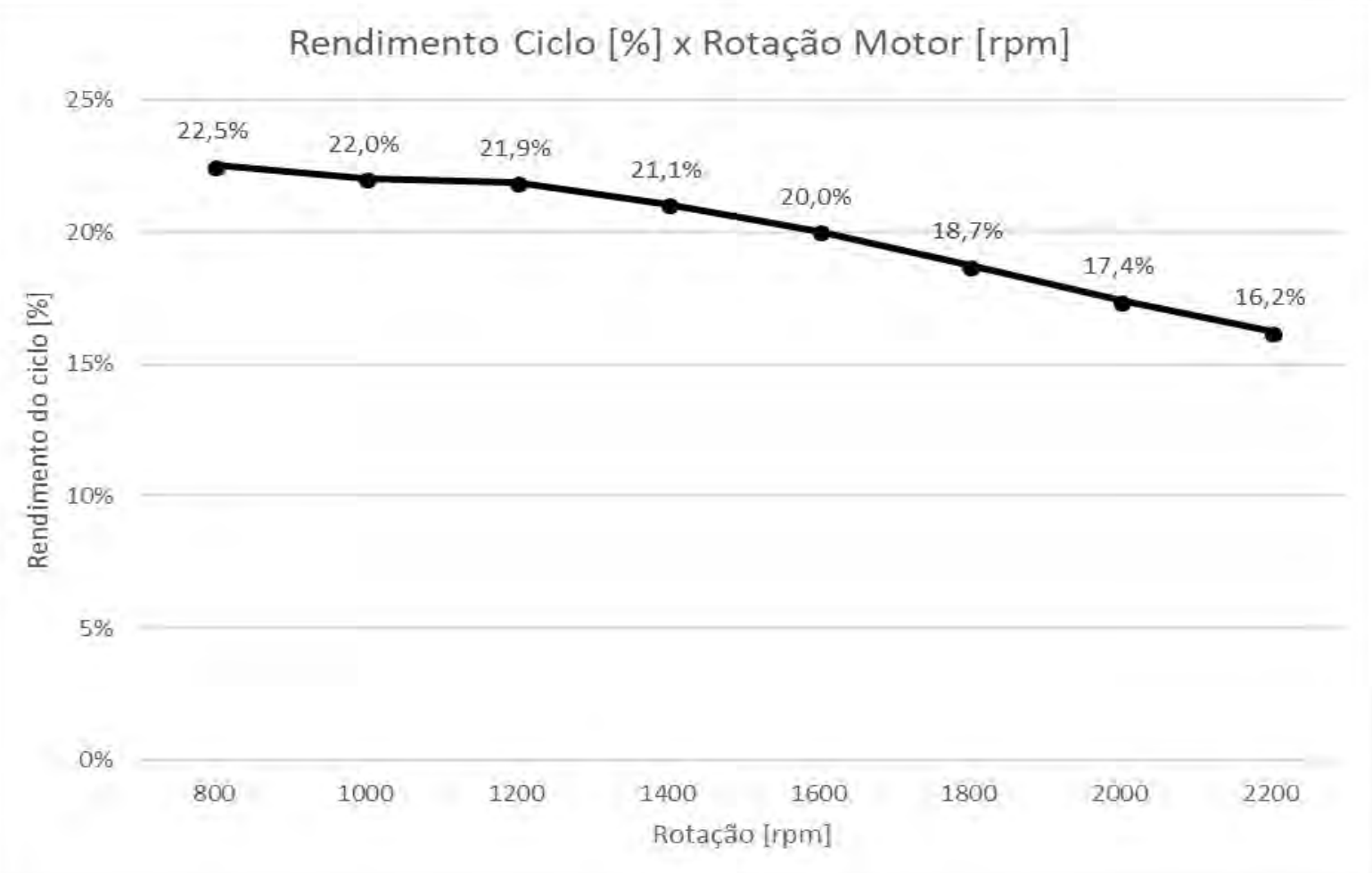

Fonte: Autores.

\section{CONCLUSÃO}

O sistema projetado se mostrou bastante eficiente na recuperação da energia desperdiçada pelos gases de escape quando utilizado o Tolueno como fluido de trabalho. Obteve-se uma potência útil de $14 \mathrm{~kW}$ com um rendimento térmico do ciclo de $22,5 \%$, porém a turbina é um componente comercial e a que melhor se enquadrou aos critérios de seleção encontrada em catálogos de fabricantes limitou a potência de saída em $10 \mathrm{~kW}$, para contornar este problema, pode-se instalar duas turbinas em série de menor capacidade, atendendo a taxa de expansão necessária para atender a variação de pressão requerida sem a necessidade de um ciclo de reaquecimento.

Observou-se que a capacidade de troca térmica da caldeira é bastante elevada, permitindo uma recuperação energética muito maior, porém existe uma grande dificuldade em realizar a condensação completa do fluido de trabalho em função da baixa velocidade de operação das máquinas agrícolas, que limita o fluxo de ar, exigindo uma área de troca térmica muito grande e extração de calor por convecção forçada.

Não se encontraram dificuldades para a montagem dos componentes no veículo selecionado, pois trata-se de um veículo de grandes dimensões que apresenta bastante espaço livre para a instalação dos componentes separadamente.

A massa total do sistema pode ser distribuída de maneira a melhorar a capacidade trativa do veículo, reduzindo a necessidade de instalação de lastros para compensar o equilíbrio dinâmico do trator, obtendo um melhor rendimento da máquina. 


\section{REFERÊNCIAS}

[1] The Boston Consulting Group (BCG). BCG forecasts electrified vehicles to take half of global auto market by 2030; hybrids to dominate. Disponível em http://www.greencarcongress.com/2017/11/20171103-bcg.html. Acesso em: maio de 2018. [2] DOMINGUES, Antônio. Avaliação do potencial de aproveitamento da energia contida nos gases de escape de veículos automóveis. Lisboa, página 3, outubro de 2011.

[3] POLOZINE, Alexandre; SCHAEFFER, Lírio. Materiais sinterizados para geração de energia elétrica. Porto Alegre, RS, páginas 1-7, outubro de 2013.

[4] University of California, Riverside (UCR). UCR team demonstrates use of earth abundant elements in spin-mediated thermoelectric energy conversion for waste heat recovery.

Disponível em http://www.greencarcongress.com/thermoelectrics/. Acesso em: maio de 2018.

[5] FAIRBANKS, John. Automotive Thermoelectric generators and HVAC. Washington, DC, páginas 2-16, maio de 2017.

[6] LION, Simone; MICHOS, Constantine N.; VLASKOS, Ioannis; TACCANI, Rodolfo. A thermodynamic feasibility study of an Organic Rankine Cycle (ORC) for heavy-duty Diesel engine waste heat recovery in off-highway applications. Trieste, páginas 82-97, abril de 2017. [7] Faurecia. Faurecia desenvolve sistema de recuperação de energia. Disponível em http://www.autoentusiastas.com.br/2016/06/faurecia-desenvolve-sistema-recuperacaoenergia/. Acesso em: maio de 2018.

[8] CARMO, Cristopher et al. PROJETO TURBUS: aplicação de turbogerador em um midiônibus. São Bernardo do Campo, SP, páginas 21-95, abril de 2016.

[9] Celiça Supra. Turbo compound. Disponível em http://www.celicasupra.com/gallery/. Acesso em: maio de 2018.

[10] Emma Steinhardt. Stirling engine. Disponível em http://estein.mit.edu/portfolio/stirlingengine/. Acesso em: maio de 2018.

[11] THOMBARE, Dhananjay; VERMA, S.K. Technological development in the Stirling cycle engines. Índia, janeiro de 2008.

[12] Ciclos de Potência a Vapor - UFSC. Disponível em http://www.polo.ufsc.br/fmanager/polo2016/materiais/arquivo6_1.pdf._Acesso em: abril de 2018.

[13] Ciclos de Potência a Vapor - UNICAMP. Disponível em http://www.fem.unicamp.br/ franklin/ES672/pdf/turbina vapor_ciclo.pdf._Acesso em: abril de 2018.

[14] ÇENGEL, Yunus; BOLES, Michael. Termodinâmica. $7^{\text {a }}$ edição, Porto Alegre: AMGH EDITORA LTDA, 2013.

[15] WENZEL, Thiago. Análise Termodinâmica e Simulação de um Ciclo Rankine Orgânico (ORC). Porto Alegre, RS, páginas 2-15, novembro de 2015.

[16] LION, Simone; MICHOS, Constantine N.; VLASKOS, Ioannis; TACCANI, Rodolfo. A review of waste heat recovery and Organic Rankine Cycles (ORC) in on-off highway vehicle Heavy Duty Diesel Engine applications. Trieste, páginas 691-708, maio de 2017.

[17] New Holland T8020. Disponível em http://www.tractordata.com/farmtractors/005/4/8/5480-new-holland-t8020.html._Acesso em: maio de 2018.

[18] Agrícola Case New Holland. Disponível em

https://www.cummins.com.br/produtos/motores/aplica $\% \mathrm{C} 3 \% \mathrm{~A} 7 \% \mathrm{C} 3 \% \mathrm{~B} 5 \mathrm{es} / \mathrm{agr} \% \mathrm{C} 3 \% \mathrm{ADco}$ la/agr\%C3\%ADcola-case-new-holland._Acesso em: maio de 2018.

[19] ÇENGEL, Yunus; GHAJAR, Afshin. Transferência de calor e massa. $4^{\mathrm{a}}$ edição, Porto Alegre: AMGH EDITORA LTDA, 2012. 